\title{
Determinants of Exercise Capacity Assessed With the Modified Shuttle Test in Individuals With Cystic Fibrosis
}

\author{
Fernanda Maria Vendrusculo, Evanirso Silva Aquino, Natália Evangelista Campos, \\ Ingrid Silveira de Almeida, João Paulo Heinzmann-Filho, Karen Caroline Vasconcelos Queiroz, \\ Luanna Rodrigues Leite, and Márcio Vinícius Fagundes Donadio
}

\begin{abstract}
BACKGROUND: Patients with cystic fibrosis develop decreased exercise capacity. However, the main factors responsible for this decline are still unclear. Thus, the objective of this study was to evaluate the factors influencing exercise capacity assessed with the modified shuttle test (MST) in individuals with cystic fibrosis. METHODS: A cross-sectional study was carried out in subjects with a diagnosis of cystic fibrosis who were 6-26 y old and were regularly monitored at 2 cystic fibrosis reference centers in Brazil. Individuals who were unable to perform the tests or who exhibited hemodynamic instability and exacerbation of respiratory symptoms were excluded. Anthropometric, clinical, and genotype data were collected. In addition, lung function and exercise capacity were evaluated with the MST. RESULTS: 73 subjects (mean age $12.2 \pm$ 4.9 $\mathrm{y}$ and $\mathrm{FEV}_{1} \mathbf{7 6 . 8} \pm 23.3 \%$ ) were included. The mean distance achieved in the MST was $765 \pm$ $258 \mathrm{~m}(\mathbf{7 1 . 6 \%}$ of predicted). The distance achieved on the MST correlated significantly with age $(\mathrm{r}=0.49, P<.001)$, body mass index $(\mathrm{r}=0.41, P<.001)$, resting heart rate $(\mathrm{r}=-0.51, P<$ $.001)$, and $\mathrm{FEV}_{1}(\mathrm{r}=0.24, P=.042)$. Subjects with $\mathrm{FEV}_{1}>67 \%$ of predicted $(P=.02)$ and those with resting heart rate $<100$ beats/min $(P=.01)$ had a greater exercise capacity. Resting heart rate, age, and $\mathrm{FEV}_{1}(\%)$ were found as significant variables to explain the distance achieved on the MST $\left(R^{2}=0.48\right.$, standard error $\left.=191.0 \mathrm{~m}\right)$. CONCLUSIONS: The main determinants of exercise capacity assessed with the MST in individuals with cystic fibrosis were resting heart rate, age, and lung function. Key words: cystic fibrosis; exercise tolerance; field tests; heart rate; lung function; oxygen consumption. [Respir Care 2020;65(5):643-649. (C) 2020 Daedalus Enterprises]
\end{abstract}

\section{Introduction}

Cystic fibrosis is a disease caused by genetic mutations in the long arm of chromosome 7. These mutations are grouped in different classes, and the most common is

Drs Vendrusculo, Heinzmann-Filho, and Donadio, and Ms Campos, Ms de Almeida are affiliated with the Laboratory of Pediatric Physical Activity, Centro Infant, Pontifícia Universidade Católica do Rio Grande do Sul, Porto Alegre, Rio Grande do Sul, Brazil. Dr Aquino, Ms Queiroz, and Ms Leite are affiliated with the Pontifícia Universidade Católica de Minas Gerais - Campus Betim, Betim, Minas Gerais, Brazil. Dr Aquino is affiliated with the Hospital Infantil João Paulo II, Belo Horizonte, Minas Gerais, Brazil.

The authors have disclosed financial support from Coordenação de Aperfeiçoamento de Pessoal de Nível Superior (finance code 001), Conselho Nacional de Desenvolvimento Científico e Tecnológico, and Fundo de Incentivo à Pesquisa da PUC Minas (FIP 11009-S2) .
F508del, which occurs in $50-70 \%$ of patients. ${ }^{1}$ The multisystemic characteristic of the disease leads to progressive loss of lung function and physical exercise intolerance. ${ }^{2}$ Exercise capacity is known to be associated with mortality in patients with cystic fibrosis and individuals with reduced oxygen consumption (peak $\dot{\mathrm{V}}_{\mathrm{O}_{2}}$ ), with values below 45 $\mathrm{mL} / \mathrm{kg} / \mathrm{min}$ ( $82 \%$ of predicted) presenting 4.9 times higher risk for a fatal outcome in an 8-y follow-up period. ${ }^{3}$

The precise mechanisms of exercise intolerance in young patients with cystic fibrosis are still controversial and

\footnotetext{
Correspondence: Márcio Vinícius Fagundes Donadio PT PhD, Laboratory of Pediatric Physical Activity, Centro Infant, Av. Ipiranga, 6690, $2^{\circ}$ andar, Porto Alegre, Rio Grande do Sul, CEP 90610-000, Brazil. E-mail: mdonadio@ pucrs.br.
}

DOI: $10.4187 /$ respcare. 07326 
appear to be influenced by several factors, including age, sex, nutritional status, lung function, genotype, chronic colonization by Pseudomonas aeruginosa, endurance and strength of the respiratory muscles. ${ }^{4-8}$ However, recently, a multicenter study demonstrated that genotype severity was not associated with exercise capacity as assessed with the cardiopulmonary exercise test, but was associated with lower lung function and poor nutritional status. $^{6}$

On the other hand, the accepted standard evaluation of peak $\dot{\mathrm{V}}_{\mathrm{O}_{2}}$ (ie, cardiopulmonary exercise testing) is still not available in most cystic fibrosis centers due to the need for equipment and staff with expertise to perform the gas analysis test. Therefore, the modified shuttle test (MST) has been validated for use in individuals with cystic fibrosis, and the MST is suggested as an alternative for the evaluation and monitoring of the exercise capacity, considering that the distance achieved on the test presents a strong correlation with peak $\dot{\mathrm{V}}_{\mathrm{O}_{2}}$ measured through cardiopulmonary exercise testing. ${ }^{9-11}$

Thus, considering the importance of identifying the mechanisms associated with exercise intolerance, this study aimed to evaluate the factors that influence exercise capacity assessed with the MST in individuals with cystic fibrosis. For that, subjects were submitted to a MST, and the associations with clinical and demographic data, lung function, and nutritional status were evaluated.

\section{Methods}

A cross-sectional study was carried out in subjects with cystic fibrosis (diagnosis confirmed with a genetic test), ${ }^{12}$ who were $6-26$ y old and were regularly monitored at 2 reference centers (Hospital São Lucas, Pontifícia Universidade Católica do Rio Grande do Sul and Hospital Infantil João Paulo II, Pontifícia Universidade Católica de Minas Gerais - Campus Betim) for cystic fibrosis treatment. Individuals with hemodynamic instability, exacerbation of respiratory symptoms (eg, fever, increased coughing, sputum production) on the day of the test, or osteoarticular or musculoskeletal abnormalities that would potentially influence the tests were excluded.

Subjects were recruited during an out-patient visit and performed the MST on the same day. Spirometry was performed by trained staff members, which is routine for both treatment centers. In addition to the tests, anthropometric, clinical, and genetic data were collected, including the type of mutation and chronic colonization by $P$. aeruginosa. Chronic colonization by $P$. aeruginosa was defined as the persistent presence of the bacterium in the oropharynx swab or sputum culture for at least 6 months or in 3 consecutive collections. ${ }^{13}$ Mutations were classified into 3 categories: F508del homozygote, F508del heterozygote, and other mutations.

\section{QUICK LOOK}

\section{Current knowledge}

The precise mechanisms of exercise intolerance in children and adolescents with cystic fibrosis are still controversial, but they appear to be influenced by several factors, including age, sex, nutritional status, lung function, genotype, chronic colonization by $P$. aeruginosa, and endurance and strength of respiratory muscles. Cardiopulmonary exercise testing is not available in most cystic fibrosis centers due to the need for equipment and staff with expertise to perform the test.

\section{What this paper contributes to our knowledge}

The determinants of exercise capacity assessed with the modified shuttle test in children and adolescents with cystic fibrosis were resting heart rate, age, and lung function. Measurement of resting heart rate, used in conjunction with age and $\mathrm{FEV}_{1}$, may be a complementary tool for evaluation and follow-up of patients with cystic fibrosis during out-patient visits because it is simple and easy to perform.

The sample size was estimated based on the relationship between the main variables demonstrated in the study by Doeleman et al. ${ }^{8}$ To identify a minimum correlation of 0.40 , with a power of $90 \%$ and significance level of $5 \%$, a minimum sample of 62 subjects was estimated. The study was approved by the Research Ethics Committee of both centers (52583416.5.0000.5336, 54142716.8.3001.5119). All legal guardians and subjects over the age of $18 \mathrm{y}$ signed the informed consent term. Moreover, children and adolescents under the age of $18 \mathrm{y}$ signed the assent form.

\section{Anthropometric Data}

Weight and height measurements were performed in triplicate or until 2 identical values were obtained. Weight was measured in the orthostatic position, with the minimum of clothing and without footwear, with the use of a digital scale (G-tech, Glass $1 \mathrm{FW}$, Rio de Janeiro, Brazil) previously calibrated with a precision of $100 \mathrm{~g}$. Height was obtained with a portable stadiometer (AlturaExata, TBW, São Paulo, Brazil) with a precision of $1 \mathrm{~mm}$, with subjects barefoot, feet parallel, ankles together, and arms extended along the body. ${ }^{14}$ Individuals were classified as malnourished and eutrophic according to World Health Organization (WHO) recommendations. ${ }^{15}$ The WHO Anthroplus program was used to calculate body mass index z-scores. ${ }^{16}$ 


\section{Determinants of Exercise Capacity in Cystic Fibrosis}

\section{Modified Shuttle Test}

The MST was performed as described by Bradley et al. ${ }^{11}$ This test has 15 levels, and patients should walk or run, when necessary, with increasing speeds on a 10-m course delimited by 2 cones (ie, a cone at each end of the course) that must be circumvented by the individual. An audio signal is an integral part of the test, representing a level change as well as the speed increase during the test. The subjects were followed up by the physiotherapist during the first minute for adaptation to the rhythm of the audio signal. The test protocol begins with an average speed of $0.5 \mathrm{~m} / \mathrm{s}$ (level 1), followed by an increment of $0.17 \mathrm{~m} / \mathrm{s}$ at each subsequent level. At the end of each level, a standardized verbal encouragement was offered for the subjects to walk faster, as well as guidance to complete the total duration of the test. Before the start of the test and immediately at the end, the heart rate, $\mathrm{S}_{\mathrm{pO}_{2}}$ (Nonin, Minneapolis), blood pressure (BIC sphygmomanometer, Itupeva, Brazil), and the modified BORG scale score for dyspnea were measured. In addition, heart rate and $\mathrm{S}_{\mathrm{pO}_{2}}$ were monitored throughout the test.

The test was completed when the subject reported an inability to continue due to exhaustion, lost the rhythm of the audio signal for 2 consecutive times, reached a maximum distance of $1,500 \mathrm{~m}$, or presented $\mathrm{S}_{\mathrm{pO}_{2}}<75 \%$. The distance achieved was calculated by counting the total number of shuttles at the end of the test and expressed in meters and percent of predicted. ${ }^{17}$ The peak $\dot{\mathrm{V}}_{\mathrm{O}_{2}}$ was estimated by the following equation: $\dot{\mathrm{V}}_{\mathrm{O}_{2}}(\mathrm{~mL} / \mathrm{kg} / \mathrm{min})=$ $20.301+0.019 \times$ MST distance $(\mathrm{m}) .{ }^{10}$

\section{Lung Function}

The assessment of lung function was performed with subjects in the orthostatic position, without the use of a nasal clip. ${ }^{18}$ All acceptability and repeatability criteria followed the recommendations of the American Thoracic Society and European Respiratory Society. ${ }^{19} \mathrm{FVC}, \mathrm{FEV}_{1}$, $\mathrm{FEV}_{1} / \mathrm{FVC}$, and the forced expiratory flow during the middle half of the FVC maneuver $\left(\mathrm{FEF}_{25-75 \%}\right)$ were evaluated. Data were expressed in absolute values and percentage of predicted, based on an international reference equation. ${ }^{20}$ For some of the analyses, the sample was divided into 2 groups: $\mathrm{FEV}_{1}<67 \%$ predicted and $\mathrm{FEV}_{1}>67 \%$. According to Doeleman et al, ${ }^{8}$ subjects with moderateto-severe cystic fibrosis $\left(\mathrm{FEV}_{1}<67 \%\right)$ present a strong association between lung function and distance achieved on the MST.

\section{Statistical Analysis}

The distribution of the variables was assessed using the Kolmogorov-Smirnov test. As a normal distribution was found, the continuous variables were presented as mean \pm SD. Categorical variables were presented in absolute and percentage frequencies. Correlations were assessed using a Pearson linear correlation test and classified as weak ( $\mathrm{r}<$ $0.4)$, moderate $(r \geq 0.4$ and $<0.7)$, and strong ( $r \geq 0.7)$. A Student $t$ test for independent samples was used for comparisons of the MST distance between different lung function, nutritional status, and resting heart rate. One-way analysis of variance with least significant difference post-test was used for comparisons of lung function, nutritional status, and distance achieved on MST between the distinct genotype categories. A multiple linear regression model was used to evaluate the influence of the variables on the distance achieved on the MST. Variables presenting the highest correlation coefficient (r) with the MST distance were included in the analysis. Considering that the majority of our sample are children and adolescents, body mass index was selected to assess nutritional status instead of height and weight. Variable selection was performed using the forward stepwise method. Only the model with the highest coefficient of determination $\left(\mathrm{R}^{2}\right)$ is presented. ${ }^{21}$ All analyses and data processing were performed with SPSS 18.0 (IBM, Armonk, New York), and the level of significance adopted was $P<.05$.

\section{Results}

A total of 73 subjects with a mean age of $12.2 \pm 4.9 \mathrm{y}$ were included; of the subjects, $65.8 \%$ were male and $57.5 \%$ were heterozygous for the F508del mutation. Regarding lung function, the mean percentage of predicted $\mathrm{FEV}_{1}$ was $76.8 \pm 23.6$ and FVC was $84 \pm 20.6$. The characteristics of the sample are presented in Table 1 . The physiological variables evaluated at rest and at the end of the MST are shown in Table 2. The mean heart rate (beats/min) was $94 \pm 15$ at rest and $178 \pm 17$ at the end of the test. The mean level reached during the MST was $11 \pm 2$, and the average distance reached was $765 \pm$ $258 \mathrm{~m}$, corresponding to $71.6 \pm 20.8 \%$ of the predicted distance. In addition, the estimated mean peak $\dot{\mathrm{V}}_{\mathrm{O}_{2}}$ was $34.8 \pm 4.9 \mathrm{~mL} / \mathrm{kg} / \mathrm{min}$.

Figure 1 shows the distance achieved on the MST correlated significantly $(P<.001)$ and moderately with age $(\mathrm{r}=$ $0.49)$, body mass index $(\mathrm{r}=0.41)$, and resting heart rate $(\mathrm{r}=-0.51)$. In addition, we found a significant and weak correlation with percentage of predicted $\mathrm{FEV}_{1}(\mathrm{r}=0.24)$. Data presented in Figure 2 show the distance achieved on the MST according to $\mathrm{FEV}_{1}$, body mass index, and resting heart rate. No differences were found regarding nutritional status. On the other hand, lung function $(P=.02)$ and resting heart rate $(P=.01)$ significantly influenced the MST distance because subjects with $\mathrm{FEV}_{1}<67 \%$ of predicted $(661 \pm 235 \mathrm{~m})$ and those with resting heart rate $>100$ beats/min $(665 \pm 206 \mathrm{~m})$ exhibited lower exercise capacity, 


\section{Determinants of Exercise Capacity in Cystic Fibrosis}

Table 1. Characterization of the Study Sample

\begin{tabular}{|c|c|}
\hline \multicolumn{2}{|l|}{ Demographic characteristics } \\
\hline Age, y & $12.2 \pm 4.9$ \\
\hline Male & $48(65.8)$ \\
\hline \multicolumn{2}{|l|}{ Anthropometry } \\
\hline Height, $\mathrm{cm}$ & $146.1 \pm 17.2$ \\
\hline Weight, $\mathrm{kg}$ & $39.7 \pm 15.2$ \\
\hline Body mass index, $\mathrm{kg} / \mathrm{m}^{2}$ & $17.4 \pm 3.5$ \\
\hline Body mass index, z-score & $-0.4 \pm 1.2$ \\
\hline \multicolumn{2}{|l|}{ Genotype } \\
\hline F508del homozygous & $19(26.0)$ \\
\hline F508del heterozygous & $42(57.5)$ \\
\hline Other mutations & $12(16.4)$ \\
\hline \multicolumn{2}{|l|}{ Chronic colonization } \\
\hline Pseudomonas aeruginosa & $14(19.2)$ \\
\hline \multicolumn{2}{|l|}{ Lung function } \\
\hline $\mathrm{FEV}_{1}, \mathrm{~L}$ & $1.9 \pm 0.9$ \\
\hline $\mathrm{FEV}_{1}, \%$ predicted & $76.8 \pm 23.6$ \\
\hline FVC, L & $2.4 \pm 1.6$ \\
\hline FVC, $\%$ predicted & $84.0 \pm 20.6$ \\
\hline $\mathrm{FEV}_{1} / \mathrm{FVC}$ (absolute) & $0.8 \pm 0.1$ \\
\hline $\mathrm{FEV}_{1} / \mathrm{FVC}, \%$ predicted & $89.9 \pm 13.1$ \\
\hline $\mathrm{FEF}_{25-75 \%}, \mathrm{~L} / \mathrm{min}$ & $1.8 \pm 1.1$ \\
\hline $\mathrm{FEF}_{25-75 \%}, \%$ predicted & $64.5 \pm 37.6$ \\
\hline
\end{tabular}

Table 2. Resting Characteristics and Physiological Responses to the Modified Shuttle Test

\begin{tabular}{lc}
\hline \hline Resting & \\
Heart rate, beats/min & $94 \pm 15$ \\
Systolic blood pressure, $\mathrm{mmHg}$ & $99 \pm 14$ \\
Diastolic blood pressure, $\mathrm{mmHg}$ & $63 \pm 9$ \\
$\mathrm{~S}_{\mathrm{pO}_{2}}, \%$ & $97 \pm 2$ \\
Frequency, breaths/min & $21 \pm 5$ \\
Borg score for dyspnea & $0 \pm 0$ \\
Peak exercise & \\
MST level & $11 \pm 2$ \\
MST distance, m & $765 \pm 258$ \\
MST distance, \% predicted & $71.6 \pm 20.8$ \\
$\dot{V}_{\mathrm{O}_{2}}$ estimated, mL/kg/min & $34.8 \pm 4.9$ \\
Heart rate, beats/min & $178 \pm 17$ \\
Systolic blood pressure, $\mathrm{mmHg}$ & $119 \pm 24$ \\
Diastolic blood pressure, $\mathrm{mmHg}$ & $69 \pm 9$ \\
$\mathrm{~S}_{\mathrm{PO}_{2}}, \%$ & $93 \pm 4$ \\
Frequency, breaths/min & $36 \pm 7$ \\
Borg score for dyspnea & $6 \pm 3$
\end{tabular}

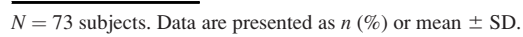

as evidenced by the decreased distance covered on the MST.

There was no influence of genotyping on the distance achieved on the MST or on lung function. However, there were significant differences for body mass index, both when the F508del homozygote was compared to the F508del heterozygote (mean difference $-2.4, P=.01$ ) and to other mutations (mean difference $-2.6, P=.038$ ). These data are presented in Figure 3.

The results of the multiple linear regression analysis for the determinants of the distance achieved on the MST are presented in Table 3. The variables of gender, age, chronic colonization by $P$. aeruginosa, body mass index, $\mathrm{FEV}_{1}(\%$ of predicted), FVC (\% of predicted), and resting heart rate were included in the analysis. The results showed that only resting heart rate, age, and $\mathrm{FEV}_{1}$ (\% predicted) were significant to explain the distance achieved on the MST, with a $\mathrm{R}^{2}=0.48$ and a standard error of the estimate of $191.0 \mathrm{~m}$. The standardized beta coefficient for resting heart rate, age, and $\mathrm{FEV}_{1}$ were $-0.328,0.490$, and 0.290 , respectively.

\section{Discussion}

This study aimed to identify factors that may influence exercise capacity assessed by the MST in young subjects with cystic fibrosis. The results showed that resting heart rate is one of the main determining factors for the distance achieved on the MST, along with age and lung function. On the other hand, genotyping appeared to have no significant influence on exercise capacity.

Resting heart rate has been used as an important indicator of physical fitness and clinical prognosis in subjects with heart disease. ${ }^{22}$ Aerobic training performed with submaximum workloads reduces heart rate at rest and during exercise. ${ }^{22}$ In addition, a study with healthy adolescents showed that aerobic fitness is associated with resting heart rate, indicating that lower aerobic fitness is associated with higher heart rate values at rest. ${ }^{23}$ Sarganas et $\mathrm{al}^{24}$ reported an association of resting heart rate with aerobic capacity in adolescents aged 11-17 y. Our data indicate a moderate correlation between resting heart rate and distance achieved on the MST. However, resting heart rate was the main variable found to explain the distance achieved on the MST $\left(R^{2}=0.26\right)$. To our knowledge, this is the first study to report that resting heart rate is a significant determinant of exercise capacity in young individuals with cystic fibrosis, and it may be a clinical marker when used in conjunction with other variables because its evaluation is simple.

Age and $\mathrm{FEV}_{1}$ (\% of predicted) were also determinants of exercise capacity according to the data of the present study. Similarly, Doeleman et $\mathrm{al}^{8}$ reported that these variables could explain $64 \%$ of the distance on the MST in adults with cystic fibrosis, although that model also included gender. In the study by Pastre et $a{ }^{25}$ the variables found to be predictors of peak $\dot{\mathrm{V}}_{\mathrm{O}_{2}}$ in adult subjects with mild to moderate pulmonary disease were $\mathrm{FEV}_{1}$ (\% of predicted), ventilatory equivalent for carbon 

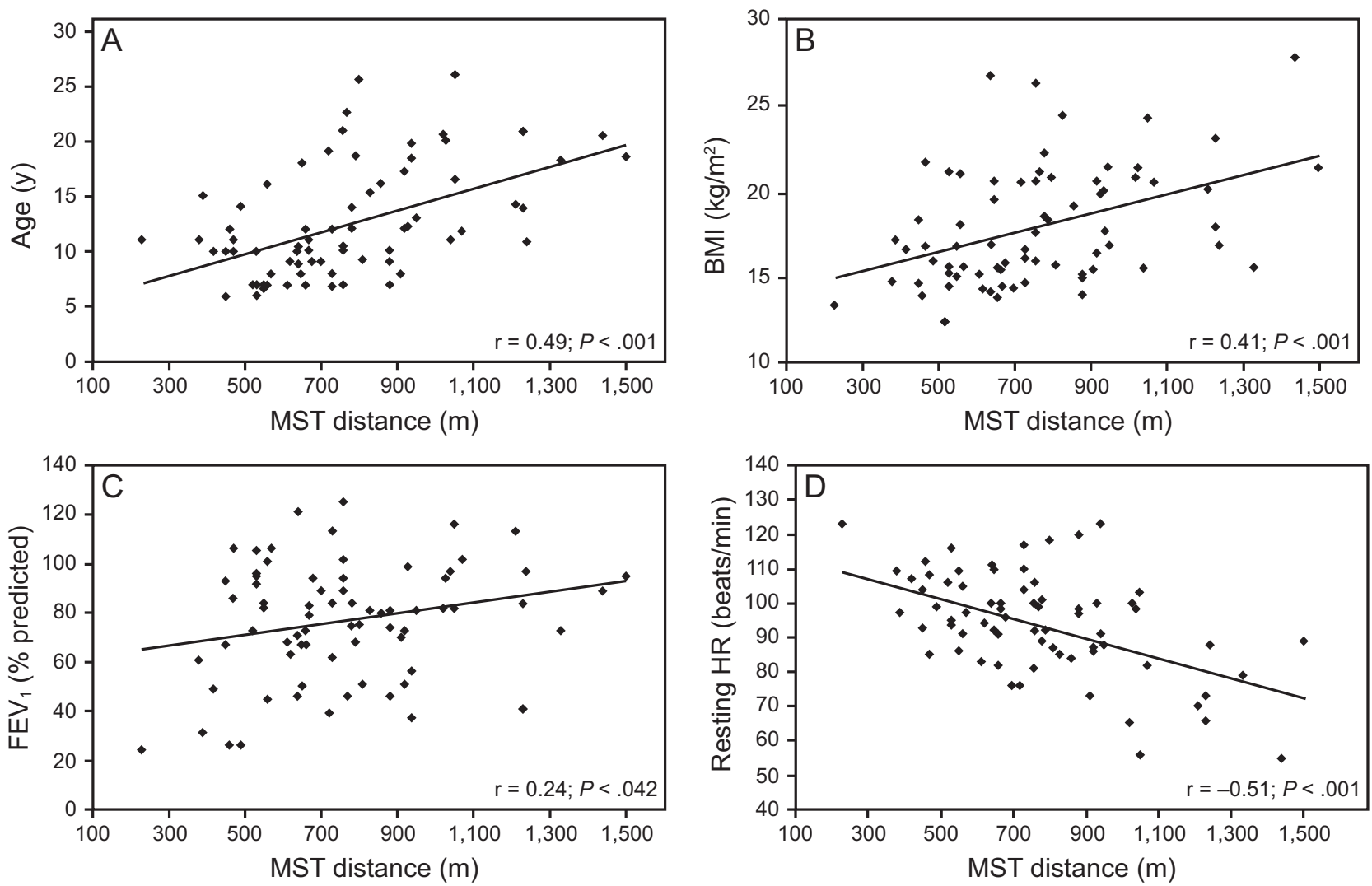

Fig. 1. Correlation between the distance achieved in the modified shuttle test (MST) and (A) age, (B) body mass index (BMI), (C) FEV 1 , and (D) resting heart rate $(\mathrm{HR})$.
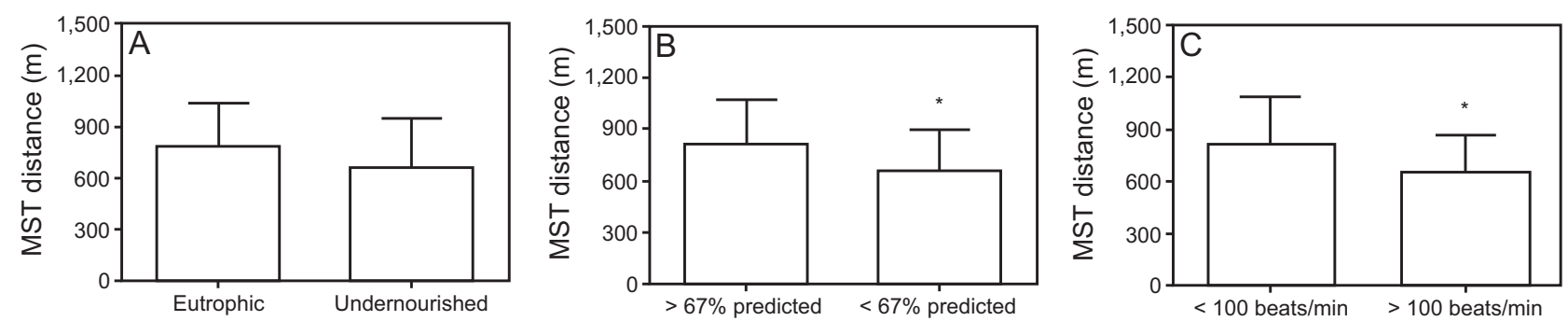

Fig. 2. Comparison of the distance achieved in the modified shuttle test (MST) between (A) eutrophic and undernourished subjects, (B) subjects with $\mathrm{FEV}_{1}$ above or below $67 \%$ predicted, and (C) subjects with resting heart rate above or below 100 beats/min. ${ }^{*}$ significant differences $(P<.05)$.

dioxide production, and ventilatory reserve, accounting for $67 \%$ of exercise capacity. Our results indicate a weak correlation between the distance covered on the MST and $\mathrm{FEV}_{1}$ (\% of predicted), contrary to the moderate correlation that was reported in previous work. ${ }^{11,26}$ In addition, Doeleman et $\mathrm{al}^{8}$ noted a strong correlation only when subjects with a $\mathrm{FEV}_{1}<67 \%$ of predicted were analyzed. Thus, when data from the present study was categorized as $\mathrm{FEV}_{1}<67 \%$ or $>67 \%$ of predicted, we noted that subjects with $\mathrm{FEV}_{1}<67 \%$ of predicted achieved a significantly lower distance on the MST. It is possible that the poor correlation found in our study may be explained by the fact that the included sample was young and presenting mildly compromised pulmonary function.

The results of this study did not indicate an association between genotype and exercise capacity in individuals with cystic fibrosis. These data corroborate results of studies by Kaplan et al, ${ }^{27}$ Van de Weert-van Leeuwen et al, ${ }^{7}$ and the recent multi-center study by Radtke et al, ${ }^{6}$ which did not identify any influences of the type of genetic mutation on peak $\dot{\mathrm{V}}_{\mathrm{O}_{2}}$. On the other hand, as expected, body mass index was worse in subjects homozygous for F508del. However, this association of genotype with body mass index was reported previously. ${ }^{6}$ 


\section{Determinants of Exercise CAPacity IN Cystic Fibrosis}
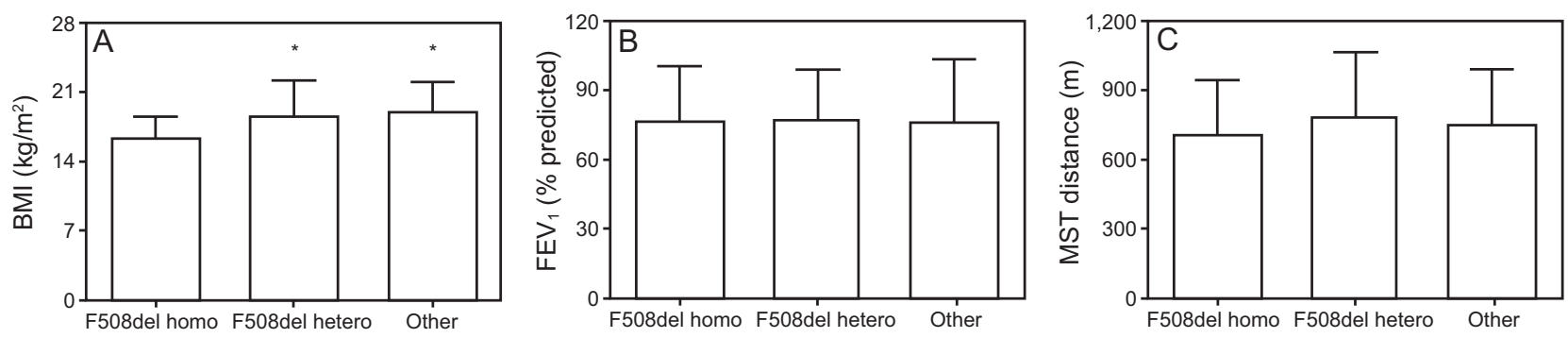

Fig. 3. Comparison of (A) body mass index (BMI), (B) $\mathrm{FEV}_{1}$, and (C) distance achieved in the modified shuttle test (MST) between different genotype categories. * significant differences $(P<.05)$ when compared to the F508del homozygote group.

Table 3. Multiple Linear Regression Model for Predicting the Distance Achieved on the Modified Shuttle Test

\begin{tabular}{lrccc}
\hline \hline & B & $\begin{array}{c}\text { Standard Error of B } \\
(95 \% \text { CI })\end{array}$ & $P$ & $\mathrm{R}^{2}$ \\
\hline Constant & 738.9 & $226.8(286.5-1,191.5)$ & $<.001$ & 0.48 \\
$\begin{array}{l}\text { Resting heart rate, } \\
\quad \text { beats/min }\end{array}$ & -5.7 & $1.6(-9.0$ to -2.4$)$ & & \\
Age, y & & & & \\
FEV $_{1} \%$ predicted & 3.2 & $1.0(1.1-5.2)$ & \\
& & & \\
\hline
\end{tabular}

One limitation of this study is the fact that the levels of daily physical activity of the subjects were not measured, which prevented us from evaluating the influence of this variable on exercise performance. However, all individuals received a recommendation for physical exercise, which is a standard guideline for all patients followed at both referral centers. It is also worth noting that the final standardized error of the estimation may be considered high, so, although results were valuable to identify the main exercise capacity determinants, values may not be used to estimate the MST distance.

\section{Conclusions}

The results of this study indicate that the determinants of exercise capacity assessed with the MST in young individuals with cystic fibrosis are the resting heart rate, age, and lung function. Measurement of resting heart rate, used in conjunction with age and $\mathrm{FEV}_{1}$, may be a complementary tool for evaluation and follow-up of patients with cystic fibrosis during out-patient visits because it is a simple and easy-to-perform method.

\section{REFERENCES}

1. Boyle MP, De Boeck K. A new era in the treatment of cystic fibrosis: correction of the underlying CFTR defect. Lancet Respir Med 2013; 1(2):158-163.

2. Nielsen KG, Pressler T, Klug B, Koch C, Bisgaard H. Serial lung function and responsiveness in cystic fibrosis during early childhood. Am J Respir Crit Care Med 2004;169(11):1209-1216.
3. Vendrusculo FM, Heinzmann-Filho JP, da Silva JS, Ruiz MP, Donadio M. Peak oxygen uptake and mortality in cystic fibrosis: systematic review and meta-analysis. Respir Care 2019;64(1):91-98.

4. Pianosi P, Leblanc J, Almudevar A. Peak oxygen uptake and mortality in children with cystic fibrosis. Thorax 2005;60(1):50-54.

5. Troosters T, Langer D, Vrijsen B, Segers J, Wouters K, Janssens W, et al. Skeletal muscle weakness, exercise tolerance and physical activity in adults with cystic fibrosis. Eur Respir J 2009;33(1):99-106.

6. Radtke T, Hebestreit H, Gallati S, Schneiderman JE, Braun J, Stevens $\mathrm{D}$, et al. CFTR genotype and maximal exercise capacity in cystic fibrosis: a cross-sectional study. Ann Am Thorac Soc 2018;15(2):209216.

7. Van de Weert-van Leeuwen P, Slieker M, Hulzebos H, Kruitwagen C, Van der Ent C, Arets H. Chronic infection and inflammation affect exercise capacity in cystic fibrosis. Eur Respir J 2012;39(4):893-898.

8. Doeleman W, Takken T, Bronsveld I, Hulzebos E. Relationship between lung function and modified shuttle test performance in adult patients with cystic fibrosis: a cross-sectional, retrospective study. Physiotherapy 2016;102(2):184-188.

9. Selvadurai HC, Cooper PJ, Meyers N, Blimkie CJ, Smith L, Mellis $\mathrm{CM}$, et al. Validation of shuttle tests in children with cystic fibrosis. Pediatr Pulmonol 2003;35(2):133-138.

10. Vendrusculo FM, Heinzmann, Filho JP, Campos NE, Gheller MF, de Almeida IS, Donadio MVF. Prediction of peak oxygen uptake using the modified shuttle test in children and adolescents with cystic fibrosis. Pediatr Pulmonol 2019;54(4):386-392.

11. Bradley J, Howard J, Wallace E, Elborn S. Validity of a modified shuttle test in adult cystic fibrosis. Thorax 1999;54(5):437-439.

12. Farrel PM, White TB, Ren CL, Hempstead SE, Accurso F, Derichs N, et al. Diagnosis of cystic fibrosis: consensus guidelines from the cystic fibrosis foundation. J Pediatr 2017;181S:S4-S15.

13. Lee TW, Brownlee KG, Conway SP, Denton M, Littlewood JM. Evaluation of a new definition for chronic Pseudomonas aeruginosa infection in cystic fibrosis patients. J Cyst Fibros 2003;2(1):29-34.

14. Borman H, Ozgür F. A simple instrument to define the Frankfurt horizontal plane for soft-tissue measurements of the face. Plast Reconstr Surg 1998;102(2):580-581.

15. World Health Organization. Physical status: the use and interpretation of anthropometry. WHO Technical Report Series \#854. Geneva: World Health Organization; 1995.

16. de Onis M, Onyango AW, Borghi E, Siyam A, Nishida C, Siekmann J. Development of a WHO growth reference for school-aged children and adolescents. Bull World Health Organ 2007;85(9):660-667.

17. de Cordoba Lanza F, do Prado Zagatto E, Silva JC, Selman JPR, Imperatori TBG, Zanatta DJM, et al. Reference equation for the incremental shuttle walk test in children and adolescents. J Pediatr 2015;167(5):1057-1061. 


\section{Determinants of Exercise CaPacity in Cystic Fibrosis}

18. Chavasse R, Johnson P, Francis J, Balfour-Lynn I, Rosenthal M, Bush A. To clip or not to clip? Noseclips for spirometry. Eur Respir J 2003;21(5):876-878.

19. Miller MR, Hankinson J, Brusasco V, Burgos F, Casaburi R, Coates A, et al. Standardisation of spirometry. Eur Respir J 2005;26(2):319338 .

20. Quanjer PH, Stanojevic S, Cole TJ, Baur X, Hall GL, Culver BH, et al. Multi-ethnic reference values for spirometry for the 3-95-yr age range: the global lung function 2012 equations. Eur Respir J 2012; 40(6):1324-1343.

21. Katz MH. Multivariable analysis: a primer for readers of medical research. Ann Intern Med 2003;138(8):644-650.

22. Moraes RS, Nóbrega A, Castro R, Negrão CE, Stein R, Serra SM, et al. Diretriz de reabilitação cardíaca. Arq Bras Cardiol 2005; 84(5):431-440.
23. Silva DAS, de Lima TR, Tremblay MS. Association between resting heart rate and health-related physical fitness in Brazilian adolescents. Biomed Res Int 2018;2018:3812197.

24. Sarganas G, Rosario AS, Neuhauser HK. Resting heart rate percentiles and associated factors in children and adolescents. J Pediatr 2017;187 (1):174-181

25. Pastré J, Prévotat A, Tardif C, Langlois C, Duhamel A, Wallaert B. Determinants of exercise capacity in cystic fibrosis patients with mildto-moderate lung disease. BMC Pulm Med 2014;14(1):74.

26. Bradley J, Howard J, Wallace E, Elborn S. Reliability, repeatability, and sensitivity of the modified shuttle test in adult cystic fibrosis. Chest 2000;117(6):1666-1671.

27. Kaplan TA, Moccia-Loos G, Rabin M, McKey JR. Lack of effect of delta F508 mutation on aerobic capacity in patients with cystic fibrosis. Clin J Sport Med 1996;6(4):226-231. 